\title{
The Effect of Negative Evaluation and Self-esteem on the Presentation Anxiety of Adolescents: The Moderated Mediation Effect of Growth Mindset
}

\author{
Chang Seek Lee, Su Hyun Park
}

\begin{abstract}
The purpose of this study was to provide policy and educational suggestions for solving the presentation anxiety of middle school students, by analyzing the moderated mediation effect of growth mindset on the relationship between negative evaluation and presentation anxiety through self-esteem. The study utilized the SPSS PC + Win. 23 and SPSS PROCESS macro 3.1. The main statistical technique used in the study was to utilize a frequency analysis, reliability analysis, correlation analysis, and moderated mediation effect analysis. In this case, the effect analysis verification utilized a bootstrap method, with 5,000 samples of sub-trap and a 95\% confidence interval. First, it is noted that the higher the negative evaluation, the higher the anxiety of presentation, and the higher the self-esteem, the lower the anxiety of presentation. Second, the growth mindset moderated the path between a negative evaluation, self-esteem, and anxiety in the participants. Based on the results of this study, suggestions for recommended future research were suggested.
\end{abstract}

Keywords : Negative Evaluation, Self-esteem, Presentation Anxiety, Growth Mindset, Moderated Mediation Effect.

\section{INTRODUCTION}

$\mathrm{P}_{\mathrm{r}}$ context of an individual anticipating making a public announcement, or actually having to perform the act of speaking in public. When a speaker makes a presentation, it refers to a burdensome phenomenon in which an audience's attention is concentrated only on oneself, as the main speaker in a group setting. At this time, the speaker becomes conscious that he is potentially being evaluated by another person. The speaker does not want to show his mistake to others because of his high self-consciousness, and develops anxiety over the process of speaking in a group. At that time, the speaker's heart is pounding, and anxiety, irritability, shame, trembling, and the anxious symptoms of a developing anxiety are experienced as amplified in those moments. Presentation anxiety is a phenomenon in which an individual is not able to express the presentation, or speak in front of a group in a public setting, which are the presentation and words that an individual has previously practiced and

Revised Manuscript Received on July 22, 2019.

* Correspondence Author

Chang Seek Lee, Dept. of Health, Counseling and Welfare, Hanseo University, 31962, Republic of Korea. Email: lee1246@ hanmail.net

Su Hyun Park*, Ph.D, Dept. of Lifelong Education, Hanseo University, 31962, Korea. Email: thank1904@ naver.com prepared for the group setting to share an idea or a thought with a group [1].

In this way, we live our lives, sharing information and ideas with each other in a way to highlight and review the complexities of life in a diverse society. However, about $40 \%$ of people around the world suffer from presentation anxiety [2] and Borkovec and O'Brien [3] found that 25\% of the general adult population felt presentation anxiety at some point in their professional lives.

Therefore, people who have difficulty in facing presentation anxiety have been variously proven not only in domestic but also in a literature review of foreign studies. It has been reported that nearly $20 \%$ of the people who experienced speaking in public and have performed most of the presentations in a population, also have difficulty in expressing or managing their own presentation anxiety [4].

These results indicate that generally speaking, that $70.3 \%$ of children and adolescents with social anxiety also experience presentation anxiety [5]. The Ayres and Raftis studies have demonstrated that people with a high level of presentation anxiety do not achieve beneficial results when they present their content in terms of content or expression, as opposed to, or rather than people with low presentation anxiety [6].

According to the Spitzberg \& Cupach study, it was also found that those who have good presentation skills are more likely to achieve their educational goals [7]. These results have been shown to be highly successful in interviewing situations and in social life events and situations experienced by most people. Therefore, adolescents with presentation anxiety are more likely to experience difficulties due to the negative influence of having anxiety regarding public speaking, which will have a negative effect on their future social life, as well as their interpersonal relationship with their friends, and can also affect their academic concentration.

On the other hand, the receiving of a negative evaluation is a fear that many people with presentation anxiety will experience, especially when the interested eyes of others will evaluate the individual's content or speech when presented in a public forum event. In other words, it is a situation where the gaze and evaluation of others who are looking at are burdened, causing the experience of an anxiety. 


\section{The Effect of Negative Evaluation and Self-esteem on the Presentation Anxiety of Adolescents: The Moderated Mediation Effect of Growth Mindset}

This brings us to understand that a negative evaluation was defined as a fear of being seen as funny by others [8]. IN that case, a negative evaluation is a state of physical, cognitive, and behavioral change that is amplified by the sub-region of social anxiety. This experience works regardless of the individual's will [9].

Negative evaluation is therefore an excessive concern for the receipt of a negative evaluation from others. Those who have a high level of fear are more likely to take action, as opposed to others who do not. The phenomenon of avoiding the presentation situation is strongly applied, in this case, because there is fear from the feeling or evaluation of others. It is difficult to achieve goals and accomplishments with fear in the background of the person's thoughts [10].

This is because the stronger the presentation anxiety, the more sensitive it is to stimulation from others. When facial expressions and disturbed behaviors of the audience appear, it leads to negative evaluation and is likely to induce presentation anxiety. Of course, the cognitive model is also concerned that it will receive a negative evaluation from others. This is in agreement with the fact that the presenters are unable to concentrate on their presentations because of their experienced negative impacts, and these are individuals who will have a strong fear when making presentations [11]. In this way, the researchers studied whether negative evaluation amplifies or maintains presentation anxiety in a way that is different from what individuals feel. A person with presentation anxiety will judge the results in advance if he or she has a desired representation when he/she is presenting and is unable to reach the desired reference value. In this presentation situation, fear caused by a negative evaluation greatly plays a role when presentation anxiety is higher rather than lower. This can give a lower rating than the ability that they have to give the speech [12]. The results of this study suggest that the higher the presentation anxiety, the more fear from receiving a negative evaluation then the lower presentation anxiety. In addition, the negative evaluation of others could be caused by a negative self-view [13].

Coopersmith [14] said that the higher the self-esteem of the individual speaking, the more dynamic and active an individual is in expressing oneself. A person with high self-esteem is successful in school life and society, and trusts himself when he makes any choice or judgment. Notwithstanding, in this case these are the individuals who believes in his own abilities and exerts his leadership in the peer group. On the other hand, a person with a low self-esteem is often seen as too careful and reluctant to participate in the group. He is not convinced of his choices and judgments, and is sensitive to other people's criticism, and easily becomes disoriented. If he also tries to solve the problem, he may experience self-centeredness. He wants to join a group social life, but an inexperienced attempt can lead him away from the peer group or away from having rather close relations or intimacy. Also, during adolescence, it is a dynamic and sensitive time for physical growth, emotional skill, expectation and change in society of an adolescence [15]. This situation is sensitive to other people's opinions and opinions during adolescence, and promotes public self-consciousness [16]. If self-esteem is low, self-confidence lacks, self-power or potential becomes negative, and inferiority and guilt feeling bad for oneself may also occur. Therefore, this may be the reason that schools, homes, and social organizations evaluate themselves negatively [17].

Self-esteem in adolescents has a strong connection with school life, especially in the case of managing a presentation task. A successful presentation experience helps improve self-esteem, but on the other hand, if it fails, it experiences presentation anxiety due to low self-esteem. For this reason, adolescents experience stress due to presentation anxiety in presentation situations. If such anxiety is experienced in a group society situation, the self-esteem of the individuals is lowered, and it is difficult to improve the positive power, and to be recognized by the organization to which the person belongs [18]. The correlation between self-esteem and presentation anxiety were found to be statistically significant among middle school students [19]. Young people with such low self-esteem may experience a feeling of low self-esteem in a desire to achieve which can be accompanied with depression and anxiety, and feel that their talents and abilities are lacking in themselves. As such, if an individual takes a passive attitude toward desired career or success, the person become isolated from the social group of peers [20]. Growth mindset is a concept proposed by Stanford University psychologist Carol Dweck after years of studying achievement and success. Mindset is a fixed mindset that believes that intelligence is fixed, and a growth mindset that believes that intelligence can be promoted and developed through continued effort and learning [21].

The fixed mindset sets the time for people to document instead of developing intelligence or talent with the belief that their temperament, such as intelligence or talent, which has fixed characteristics. It is also believed to be able to create success without effort. That is, a person with a fixed mindset tends to avoid challenges because he feels he is not capable of rising to the occasion and performing, and tends to show low resilience when he encounters obstacles. Growth mindset, on the other hand, is seen as an opportunity to learn when faced with challenges, believing that people can be motivated as a result of hard work, and shows high resilience as part of learning when encountering obstacles. Growth mindset studies have shown success in academic, social relations in adults and children, work, and emotional and physical health [22]. In relation to a study, growth mindset education for students also blocks negative stereotypes that hinder learning motivation, academic achievement and achievement of academic achievement. In addition, a class of students of teachers with high growth mindsets also had a higher academic achievement, than a class of students with low growth mindset, because they believe that their own intelligence can be developed under the influence of teachers, and thus when there are obstacles, whereby the students respond to flexibly [23].

This growth mindset has been reported to have moderating and mediating effects in a number of studies. In a study of middle school students, growth mindset moderated the relationship between self-esteem and school violence experience [24]. In a study of adults, 
it is noted that the growth mindset moderated the relationship between authentic leadership and organizational effectiveness [25]. In a study of middle school students, self-esteem showed a double mediation effect in the relationship between stress and happiness [26], and growth mindset showed a moderated mediation effect of the relationship between parental abuse and school violence victimization through self-esteem [27]. These results suggest that the growth mindset may moderate the relationship between self-esteem and presentation anxiety, and moderate the mediating effect of self-esteem in the relationship between negative evaluation and presentation anxiety.

However, there is no research noted on the relationship between variables, such as the growth mindset and presentation anxiety, although until recently, there have been many studies on the variables that cause presentation anxiety. Especially it is noted that the study on the presentation anxiety of the middle school students who are adolescents is relatively insufficient and more research on this is needed.

The purpose of this study was to provide a policy and educational proposal for solving the presentation anxiety of middle school students, by analyzing the moderated mediation effect of growth mindset on the relationship between negative evaluation and presentation anxiety through self-esteem. Research questions to achieve this objective are as follows. First, what is the correlation between adolescent negative evaluation, self-esteem, growth mindset, and presentation anxiety? Second, does the growth minds moderate the mediating effect of self-esteem on the relationship between negative evaluation and presentation anxiety?

\section{RESEARCH METHOD}

\section{A. Research model}

The research model is set as shown in Figure 1. In order to measure whether growth mindset moderates the path from the negative evaluation to presentation anxiety via self-esteem, the following research model was initiated.

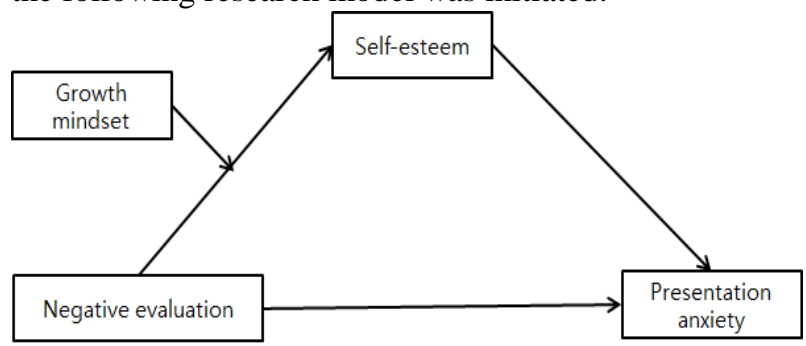

Figure 1: Research model

\section{B. Research subjects and data collection methods}

First of all, we randomly sampled three cities in Chungcheongnam province and selected a total of 6 schools after selecting 2 junior high schools by city, and finally sampled 363 students in order that 1, 2, and 3 grades were evenly distributed among them. First, 30 participants of middle school students conducted preliminary surveys. After that we reviewed, and revised and supplemented questionnaires. We explained the purpose of the study to the research subjects, and distributed and collected the questionnaire directly.

The subjects of this study were $48.8 \%$ (177) of male students and $51.2 \%$ (186) of female students. By grade, $15.2 \%$ (55) were first grade students, $70.5 \%$ (256) second grade students, and $14.3 \%$ (52) third grade students.

\section{Measuring tools}

\section{Negative evaluation}

We used the Fear of Negative Assessment Scale (BFNE) which was developed by Watson and Fried [28], and translated and used by Lee and Choi [29]. This scale is a total of 11 items that measure other people's thoughts, bad impressions, an individual's shortcomings, other people's evaluations, anxieties, and mistakes of words as spoken by an individual when communicating to others in a peer or otherwise public communication situation. Each item is rated on a 5-point Likert scale from " $1=$ not at all" to " $5=$ very agree". A higher score means higher negative evaluation. In this study, the Cronbach alpha for negative evaluation was .830 .

\section{Self-esteem}

We used a self-esteem scale developed by Rosenberg [30]. This scale consisted of 10 items in total, and each item was rated on 5 points Likert scale from a "1=not at all" to a "5=very agree." The higher the score, the higher the self-esteem of the individual studied. In this study, the Cronbach's alpha for self-esteem was .853 .

\section{Growth mindset}

We used a growth mindset scale which was developed by Dweck [31] and used by Hwang and Lee [32]. The scale consisted of 4 items measuring beliefs about change in intelligence and 4 items measuring beliefs about personality change. Each item was rated on 5 points Likert scale from a " $1=$ not at all" to a "5=very agree." The higher the score, the higher the growth mindset determined and measured in the individual. In this study, the Cronbach's alpha for growth mindset was .808 .

\section{Presentation anxiety}

In order to test presentation anxiety, the scale used in the study of Yoo [33] was used. A total of 24 items were rated on a 5-point Likert scale from " $1=$ not at all" to " $5=$ very agree." The higher the score, the higher the level of presentation anxiety. In this study, the Cronbach's alpha for presentation anxiety was .975 .

\section{Data Analysis}

The data were analyzed using SPSS PC + Win. 23 and SPSS PROCESS macro 3.2. The main statistical techniques utilized were frequency analysis, reliability analysis, correlation analysis, and moderated mediation effect analysis. For the measurement of the effect analysis verification a bootstrap was used with 5,000 samples of bootstrap and 95\% confidence interval. 


\section{RESULTS AND DISCUSSION}

\section{A. Correlation of Main Variables}

A Pearson correlation analysis was performed in this case to determine the correlation between the relevant variables. The results are shown in Table 1 . Broadly speaking, the negative evaluation showed a negative correlation with self-esteem and growth mindset, and the negative evaluation showed a positive correlation with presentation anxiety. Specifically, the self-esteem and presentation anxiety correlation coefficients were the highest at $\mathrm{r}=.432(\mathrm{p}<.01)$, and correlation coefficients of the negative evaluation and self-esteem $r=-.423$ ( $\mathrm{p}<.01)$ were followed. On the other hand, the correlation coefficient of growth mindset and presentation anxiety was lowest at $r=-.280(p<.05)$. These results are consistent with the findings that higher middle school students are more likely to be rejected or to be unrecognized in school life, because their friends or others improperly assessed their ability to communicate effectively with others in their peer group. This study is consistent with the finding that adolescents with low self-esteem experienced anxiety, depression, and low achievement levels [34].

It is noted in this case that the descriptive statistics analysis showed negative average, self-esteem, and growth mindset scores were higher than average ( 3 points), but presentation anxiety was lower (2.3045 points) than the average.

Table 1: The correlation coefficients and descriptive statistics

\begin{tabular}{|c|c|c|c|c|}
\hline & 1 & 2 & 3 & 4 \\
1. Negative evaluation & 1 & & & \\
\hline 2. Self-esteem & $-.425^{* *}$ & 1 & & \\
\hline 3. Growth mindset & $-.177^{* *}$ & $.363^{* *}$ & 1 & \\
\hline 4. Presentation anxiety & $.432^{* *}$ & $-0.423^{* *}$ & $-0.280^{* *}$ & 1 \\
\hline M & 3.0053 & 3.6164 & 3.6086 & 2.3045 \\
\hline SD & .59548 & 0.63649 & 0.62196 & 0.90841 \\
\hline${ }^{* * *} p<0.01$ & & & & \\
\hline
\end{tabular}

\section{B. Moderated mediation effect of growth mindset in the relationship between negative evaluation, self-esteem, and presentation anxiety}

In order to test whether the mediating effect of self-esteem in negative evaluation and presentation anxiety is moderated by growth mindset, we analyzed using a Model 14 of SPSS PROCESS macro proposed by Hayes [35]. In the bootstrap verification, the number of samples was set to 5,000, the confidence interval was set to $95 \%$, and the negative evaluation and the growth mindset value were centered on the average.

As was shown, the analysis results are shown in Figure 2 and Table 2. In the model with self-esteem as a dependent variable, the interaction term between negative evaluation and growth mindset was significant $(.2035, \mathrm{p}<.001)$. The R2 increase $(\mathrm{R} 2=.0175, \mathrm{p}<.001)$ due to negative evaluation and growth mindset interaction terms was also significant. Therefore, the moderating effect of growth mindset was verified.

Next, the conditional effects of independent variable,

negative evaluation, were measured on the M-SD, M, and $\mathrm{M}+\mathrm{SD}$ values of the growth mindset. In this way, the conditional effect of the negative evaluation according to the growth mindset was significant in the M-SD, M, and M + SD values of the growth mindset. As the results of analyzing conditional effects of the negative evaluation at values of growth mindset by using the Johnson-Neyman significance region, the conditional effect of negative evaluation according to the growth mindset was significant when the growth mindset value was lower than 1.1740 , but not when it was higher than that number. Such tendency was lower in the high group of growth mindset when compared to medium and lower group of growth mindset as shown in Figure 2.

In the mediating model, the negative evaluation had a significant effect on the self-esteem, and the self-esteem had a significant influence on the presentation anxiety again, in order that the self-esteem mediated in the relationship between the negative evaluation and the presentation anxiety.

The conditional indirect effect, which is the moderated mediation effect of the growth mindset, was proved to be statistically indirect by the values of Mindset, M-SD, M, and $\mathrm{M}+\mathrm{SD}$. Therefore, the moderating effect of the path between negative evaluation $\rightarrow$ self-esteem $\rightarrow$ presentation anxiety was verified. Consequently, these results are consistent with the results that growth mindset moderated mediating role in the relationship among parental abuse, self-esteem, and school violence in middle school students [36].

Table 2: Moderated mediation effect analysis of growth mindset

\begin{tabular}{|c|c|c|c|c|c|c|}
\hline variables & Effect & SE & $\mathrm{t}$ value & $p$ & LLCI $^{*}$ & $\mathrm{ULCI}^{*}$ \\
\hline \multicolumn{7}{|c|}{ Mediating variable model(DV: Self-esteem) } \\
\hline Variables & Effect & SE & $\mathrm{t}$ value & $\mathrm{P}$ & LLCI $^{*}$ & ULCI $^{* *}$ \\
\hline Constant & 3.6301 & .0287 & 126.490 & .0000 & 3.5737 & 3.6866 \\
\hline $\begin{array}{l}\text { Negative } \\
\text { evaluation }\end{array}$ & -.4153 & .0486 & -8.5364 & .0000 & -.5109 & -.3196 \\
\hline $\begin{array}{l}\text { Growth } \\
\text { mindset }\end{array}$ & .3317 & .0477 & 6.9535 & .0000 & .2379 & .4255 \\
\hline $\begin{array}{l}\text { Negative } \\
\text { evaluation } \mathrm{x} \\
\text { Growth } \\
\text { mindset }\end{array}$ & .2035 & .0688 & 2.9594 & .0033 & 0.683 & .3387 \\
\hline \multicolumn{7}{|c|}{ Test of highest order unconditional interaction: } \\
\hline $\begin{array}{l}\text { Interaction } \\
\text { item }\end{array}$ & \multicolumn{2}{|c|}{$\mathrm{R}^{2}$} & \multicolumn{2}{|c|}{$\mathrm{F}$} & \multicolumn{2}{|c|}{$p$} \\
\hline $\begin{array}{l}\text { Negative } \\
\text { evaluation } \mathrm{x} \\
\text { Growth } \\
\text { mindset }\end{array}$ & \multicolumn{2}{|c|}{.0175} & \multicolumn{2}{|c|}{8.7578} & \multicolumn{2}{|c|}{.0033} \\
\hline \multicolumn{7}{|c|}{ Conditional effects of the negative evaluation at values of growth mindset: } \\
\hline $\begin{array}{l}\text { Growth } \\
\text { mindset }\end{array}$ & Effect & se & $\mathrm{t}$ & $\mathrm{p}$ & LLCI $^{*}$ & ULCI $^{* *}$ \\
\hline-.6216 & -.5417 & .0681 & -7.9571 & .0000 & -.6756 & -.4078 \\
\hline .0000 & -4153 & .0486 & -8.5364 & .0000 & -.5109 & -.3196 \\
\hline .6216 & -2888 & .0612 & -4.7155 & .0000 & -.4092 & -.1683 \\
\hline \multicolumn{7}{|c|}{ Conditional effect of the negative evaluation at growth mindset } \\
\hline $\begin{array}{l}\text { Growth } \\
\text { mindset }\end{array}$ & Effect & se & $\mathrm{t}$ & $p$ & LLCI & ULCI \\
\hline-.1 .7321 & -.7677 & .1333 & -5.7572 & .0000 & -1.0299 & -.5054 \\
\hline 1.0804 & -.1954 & .0844 & -2.3170 & 0211 & -.3613 & -.0296 \\
\hline 1.1740 & -.1764 & .0897 & -1.9666 & .0500 & -3528 & -.0000 \\
\hline 1.2367 & -1637 & .0934 & -1.7530 & .0805 & -3472 & .0199 \\
\hline 1.3929 & -.1319 & 1027 & -1.2840 & 2000 & -.3338 & .0701 \\
\hline \multicolumn{7}{|c|}{ Dependent variable model (DV : Presentation anxiety) } \\
\hline Constant & 3.7941 & .2633 & 14.4098 & .0000 & 3.2763 & 4.3119 \\
\hline
\end{tabular}




\begin{tabular}{|c|c|c|c|c|c|c|}
\hline $\begin{array}{l}\text { Negative } \\
\text { evaluation }\end{array}$ & .4702 & .0766 & 6.1392 & .0000 & .3196 & .6208 \\
\hline Self-esteem & -.4109 & .0719 & -5.7144 & .0000 & -.5523 & -.2695 \\
\hline \multicolumn{7}{|c|}{$\begin{array}{c}\text { Conditional indirect effect of } \mathrm{x} \text { on y (Negative evaluation } \rightarrow \text { Self-esteem } \rightarrow \text { Presentation } \\
\text { anxiety) }\end{array}$} \\
\hline $\begin{array}{l}\text { Growth } \\
\text { mindset }\end{array}$ & \multicolumn{2}{|c|}{\begin{tabular}{l|l} 
Effect &
\end{tabular}} & Boot se & Boot LLCI ${ }^{*}$ & \multicolumn{2}{|c|}{ Boot ULCI $^{* *}$} \\
\hline-.6216 & \multirow{2}{*}{\multicolumn{2}{|c|}{.2226}} & .0537 & \multirow{2}{*}{$\begin{array}{l}.1268 \\
.0985\end{array}$} & \multicolumn{2}{|c|}{.3344} \\
\hline .0000 & & & .0398 & & \multirow{2}{*}{\multicolumn{2}{|c|}{.2542}} \\
\hline .6216 & \multicolumn{2}{|c|}{.1187} & .0361 & .0562 & & \\
\hline
\end{tabular}

*LLCI=boot Lower bound on $95 \%$ confidence interval of indirect effect $* *$ ULCI=boot Upper bound on $95 \%$ confidence interval of indirect effect

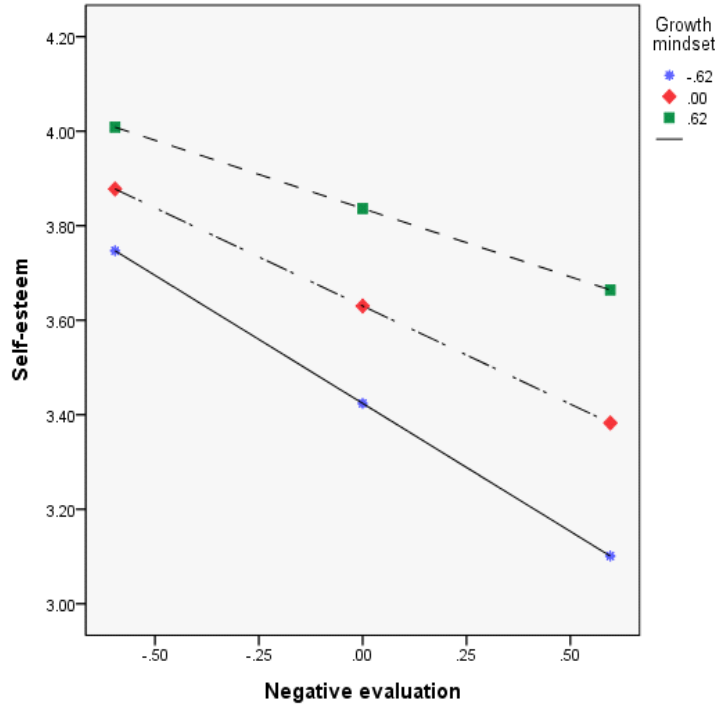

Figure 2: The moderated effect of growth mindset on the relationship between negative evaluation and self-esteem

\section{CONCLUSION}

The purpose of this study was to provide policy and educational suggestions for solving the presentation anxiety of middle school students, by analyzing the moderated mediation effect of growth mindset on the relationship between negative anger evaluation and presentation anxiety, through the measurement of self-esteem in middle school students. The results of this study are as follows.

First, a correlation analysis was conducted to investigate the relationship among negative evaluation, self-esteem, growth mindset, and presentation anxiety of junior high school students. As a result, it was shown that the higher the negative evaluation, the higher the presentation anxiety, and the higher the self-esteem, the lower the presentation anxiety. Second, the moderated mediation effect of a growth mindset was examined through conditional indirect effect validation, and the moderated mediation effect growth mindset on the relationship among negative evaluation, self-esteem and presentation anxiety was verified. In other words, the moderated mediation effect of growth mindset in the path between negative evaluation $\rightarrow$ self-esteem $\rightarrow$ presentation anxiety was verified.

Based on the results of this study, suggestions for future research are as follows. First, this study was aimed at middle school students in the Chungcheong area. In order to generalize the research results, this study should be extended not only to junior high school students in nationwide area, but also to various subjects in other grades at school. Second, the scale of this survey was filled out by a self-entry method and written by the subjective thoughts of the participants. Therefore, it is necessary to utilize objective measurement method and to measure specific changes through experimental research. The middle school students of this study were purposively sampled from a group of general students. In subsequent research, the selection and survey of samples with high presentation anxiety will lead to accurate research results.

\section{ACKNOWLEDGMENT}

This paper was undertaken with the support of a research grant in 2018 from the Hanseo University.

\section{REFERENCES}

1. G. L. Paul, D. T. Shannon. "Treatment of anxiety through systematic desensitization in therapy groups." Journal of Abnormal Psychology, 71(2), 124-135, 1966.

2. P. K. Wilbur. Stand up, Speak up, or Shut up: A practical guide to public speaking. New York: Dembner Books, 1981.

3. T. D. Borkovec, G. T. O' 'Brin. Methodological and target issues in analogue therapy outcome research. In H. E. Eisler, P. Miler. (Eds.) Progress in behavior modification. New York: Academic Press, 1976.

4. W. J. Fremouw, J. L. Breitenstein. Speech anxiety. In H. Leitenberg. (Ed.), Handbook of social and evaluation anxiety. N. Y.: Plenum Press, 1990.

5. S. Knappe, K. Beesdo-Baum, L. Fehm, M. B. Stein, R. Lieb, Wittchen $\mathrm{Hu}$. "Social fear and social phobia types among community youth: Differential clinical features and vulnerability factors." Journal of Psychiatric Research, 45(10), 111-120, 2011.

6. J. Ayres, S. M. Raftis. "The impact of evaluation and preparation time on high public speaking anxious speakers' thoughts, behavior, and state communication apprehension." Southern Journal of Communication, 57(4), 323-327, 1992.

7. B. H. Spitzberg, W. R. Cupach. Interpersonal skills, In M. L. Knapp, J. A. Daly. (Eds.) Handbooks of interpersonal communication. Thousand Oaks, CA: sage, 2002.

8. I. M. Marks, M. Gelder. "Differences of onset in varieties of phobia." American Journal of Psychiatry. 123, 218-221, 1996.

9. D. M. Clark, A. Wells. A cognitive model of social phobia, In R. G. Heimberg, M. R. Leibowitz, D. A. Hope, \& F. R. Schneier (Eds.). Social phobia diagnosis, assessment, \& treatment. New York: Guilford press, 1995.

10. N. L. Kocovski, N. S. Endler. "Social anxiety, self-regulation, and fear of negative evaluation.” European Journal of Personality, 14, 347-358, 2000

11. D. M. Clark, A. Wells. A cognitive model of social phobia In Heimberg RG, Liebowitz MR. Hope. In Schneier FR. (Eds.), Social phobia: Diagnosis, assessment, and treatment. New York: Guilford press, 1995

12. R. M. Rapee, R. G. Heimbeg. "A cognitive behavioral model of anxiety in social phobia." Behavior research and therapy, 35(8), 741-756, 1997.

13. C. R. Hirsch, D. M. Clark. "Information processing in social phobia: a critical review." Clinical psychology review, 24, 799-825, 2004.

14. S. Coopersmith. "The antecedents of self-esteem." San Francisco, Ca: W. H, 1967.

15. S. Harter. The construction of the self: Developmental and sociocultural foundations (2nd ed.). New York: Guilford press, 2012.

16. J. S. Eccles, R. W. Roeser. Schools, academic motivation, and stage-environment fit. In R. M. Lerner \& L. Steinberg (Eds.). The handbook of adolescent psychology: Vol. I. Individual bases of adolescent development. New York: Wiley, 2009.

17. B. A. Farber. Crisis in education Stress and burnout in the American teacher. San Francisco: Jossey Bass, 1991.

18. S. Leone, J. Gumaer. "Group assertiveness training of shy children." Journal of the School Counselor, 27(2), 34-141, 1979.

19. M. Rosenberg. Society and the adolescent self-image. New York: Basic books, Inc., 1979.

20. C. S. Dweck. Self-theories: Their role in motivation, personality and development. Philadelphia: Taylor and Francis/Psychology press, 1991 
21. C. S. Dweck. "Mindsets and human nature: Promoting change in the middle east, the schoolyard, the racial divide, and willpower." American Psychologist, 67(8), 614-622, 2012. DOI: 10.1037/a0029783.

22. L. Blackwell, K. Trzesniewski, C. S. Dweck. "Implicit theories of intelligence predict achievement across an adolescent transition: A longitudinal study and intervention." Child development, 78, 246-263, 2007.

23. Y. K. Hwang, C. S. Lee. "Victimization of adolescents by parental abuse and school violence: A moderated mediation model of self-esteem and growth mindset." International Journal of Pure and Applied Mathematics, 118(19), 1439-1452, 2018.

24. Y. K. Hwang, C. S. Lee. "Relationship between stress and happiness in middle school students: Dual mediation effect of growth mindset and self-esteem." Medico-Legal Update, 18(1):, 248-253, 2018. DOI • 10.5958/0974-1283.2018.00096.8

25. C. S. Lee. "Authentic leadership and organizational effectiveness: The roles of hope, grit, and growth mindset." International Journal of Pure and Applied Mathematics, 118(19), 1439-1452, 2018.

26. Y. K. Hwang, C. S. Lee. "Relationship between stress and happiness in middle school students: Dual mediation effect of growth mindset and self-esteem." Medico-Legal Update, 18(1), 248-253, 2018. DOI • 10.5958/0974-1283.2018.00096.8

27. Y. K. Hwang, C. S. Lee. "Victimization of adolescents by parental abuse and school violence: A moderated mediation model of self-esteem and growth mindset." International Journal of Pure and Applied Mathematics, 118(19), 1439-1452, 2018.

28. D. Watson, R. Friend. "Measurement of social-evaluative anxiety. Journal of Consulting and Clinical Psychology." 33(4), 448-457, 1969.

29. J. Y. Lee, C. H. Choi. "A study of the reliability and the validity of the Korean versions of social phobia scales (K-SAD, K-FNE)." Korean Journal of Clinical Psychology, 16(2), 251-264, 1997.

30. M. Rosenberg. Self-concept from middle childhood through adolescence. In Suls J. and Greenwald AG (Eds). Psychological perspectives on the self, 1968.

31. D. C. Molden, C. S. Dweck. "Finding meaning in psychology: A lay theories approach to self-regulation, social perception, and social development." 61(3), 192-203, 2006. DOI: 10.1037/0003-066X.61.3.192

32. Y. K. Hwang, C. S. Lee. "The moderating effect of growth mindset on the relationship between academic grades and self-esteem." Journal of Engineering and Applied Sciences, 13(4), 3848-3852, 2018.

33. T. Y. Yoo. "Influence of self-expression program on interpersonal anxiety and anxiety of children in elementary school and lower secondary school" Master's Thesis, Chungbuk National University, 2001

34. J. L. Deffenbacher, W. A. Zwemer, M. A. Whisman, R. A. Hill, R. D. Sloan. "Irrational beliefs and anxiety L. Deffenbacher, anxiety." Cognitive therapy and research, 10(3), 281-292, 1986.

35. A. F. Hayes. Introduction to mediation, moderation, and conditional process analysis: A regression based approach. New York: The Guilford Press, 2018.

36. Y. K. Hwang, C. S. Lee. "Victimization of adolescents by parental abuse and school violence: A moderated mediation model of self-esteem and growth mindset." International Journal of Pure and Applied Mathematics, 118(19), 1439-1452, 2018

\section{AUTHORS PROFILE}

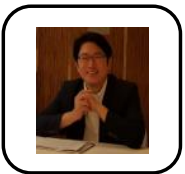

Chang Seek Lee received Bachelor's and Master's degree in lifelong education from Seoul Nationa University in Korea and Ph.D. in lifelong education from University of the Philippines in the Philippines in 1991. $\mathrm{He}$ is chairman of health, counseling and welfare department of Hanseo University, South Korea and Head of Multicultural Education and Welfare Institute of Hanseo University. His primary research interests are program development, lifelong education and multicultural education.

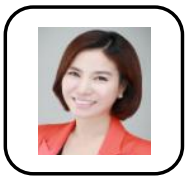

Su Hyun Park received Bachelor of Social Welfare from Sejong Cyber University in 2010, Master of Strategic Communications from Kyunghee University in 2014, and $\mathrm{Ph} . \mathrm{D}$. in Lifelong Education from Hanseo University in 2019, Korea. She runs Korea Dream Speech Academy and her main research interest is Communication. 